\title{
Small bowel necrosis as a consequence of spontaneous deflation and migration of an air-filled intragastric balloon - a potentially life-threatening complication
}

\author{
Robert Drozdowski ${ }^{1}$, Mariusz Wyleżoł², Mariusz Frączek ${ }^{3}$, Piotr Hevelke ${ }^{4}$, Marcin Giaro², Paweł Sobański ${ }^{2}$ \\ ${ }^{1}$ Department of Internal Medicine, Military Institute of Aviation Medicine, Warsaw, Poland \\ ${ }^{2}$ Department of Surgery, Military Institute of Aviation Medicine, Warsaw, Poland \\ ${ }^{3}$ Departament of General, Transplant and Liver Surgery, Medical University of Warsaw, Poland \\ ${ }^{4}$ St. Anna's Hospital, Warsaw, Poland
}

Videosurgery Miniinv 2014; 9 (2): 292-296

DOI: $10.5114 /$ wiitm.2011.38177

\begin{abstract}
Intragastric balloon placement is a common method of treatment of obesity and is often used by non-surgical teams in endoscopy departments. The likelihood of spontaneous intragastric balloon damage is a well-known phenomenon. We describe a patient who was disqualified from surgical obesity treatment and in whom intragastric fluid-filled balloons had already been inserted twice and removed due to their intolerance. Therefore we qualified this patient for placement of the air-filled balloon Heliosphere BAG. Two months after the planned check-up, he arrived at the surgery department complaining of nausea and vomiting and due to symptoms of ileus diagnosed with an X-ray and ultrasound examination we qualified him for emergency surgery. We would like to emphasise the following issues: the necessity of air-filled balloon removal according to the producer's instructions and multidisciplinary specialist team care along with appropriate diagnostic tools in every case of intragastric balloon insertion.
\end{abstract}

Key words: mechanical ileus, intragastric balloon, obesity, treatment.

\section{Introduction}

Morbid obesity is the indication for surgical treatment known as bariatric surgery. There are still discussions concerning which procedure should be performed on a particular patient [1-4]. Although great progress has been achieved in bariatric surgery in recent years, it is still not free of life-threatening complications [5-7]. The risk is one of the causes which has led to development of the potentially less invasive, endoscopic technique which can support bariatric surgery. The use of endoscopic methods in the treatment of obesity has been increasingly popular among patients, doctors and surgeons in recent years. However, most of them are experimental in nature and are still being researched [8-12]. It is likely that they will be widely accepted and implement- ed. At present, the only commonly approved endoscopic method of obesity treatment is intragastric balloon placement. This method is used for the purpose of short-term therapy to reduce body mass and minimize health risks related to obesity. It may also be performed in super obese patients with the presence of contraindications for surgery due to multiple comorbidities. In such cases, endoscopic intragastric balloon insertion is the first step of the treatment allowing body mass reduction and general health improvement [13-15]. The general opinion of intragastric balloon placement is that it is an absolutely safe procedure without complications that does not require a planned follow-up appointment [16-18]. The case presented below shows the occurrence of a lifethreatening complication requiring immediate surgical intervention. 


\section{Case report}

The described patient is a white man, aged 62 , body mass $180 \mathrm{~kg}, 1.76 \mathrm{~m}$ tall, body mass index (BMI) $58.1 \mathrm{~kg} / \mathrm{m}^{2}$. The patient has been obese since his early childhood. At the age of 10 , he weighed $85 \mathrm{~kg}$. At 40 , he stopped smoking, which caused a sudden weight gain of 8-10 kg per year. Many conservative treatment attempts did not bring therapeutic results. A BioEnterics Intragastric Balloon was inserted twice in another hospital: in December 2008 and in March 2009. Both attempts were unsuccessful and resulted in the earlier than planned removal of the balloons due to their intolerance, general discomfort, constant abdominal pain and vomiting causing dehydration and dyselectrolytaemia. The patient was disqualified from surgical treatment under general anaesthesia due to comorbidities and the high risk of postoperative complications. Therefore, we qualified this patient for placement of the air-filled balloon Heliosphere BAG. We suspected that in accordance with general opinions on air-filled balloons, this patient would tolerate it better in comparison to the previously inserted fluid-filled balloons. This procedure was planned to be an initial step before definitive surgical treatment. On 3 November 2010, the Heliosphere $\mathrm{BAG}^{\circledR}$ balloon was endoscopically inserted into the patient's stomach according to the manufacturer's instructions. The patient was discharged home in a stable condition and he was given further treatment recommendations. He was also advised that the balloon should be kept in place no longer than 180 days after the time of its insertion (Photos 1-3).

On 13 July 2011, which was over two months after the planned removal of the balloon, the patient arrived at the surgery department complaining of nausea and vomiting. Using a naso-gastric tube, about $5 \mathrm{I}$ of residual gastric contents were evacuated and upper gastrointestinal endoscopy was performed afterwards.

The balloon was not found either in the stomach or in the duodenum. An X-ray examination showed the presence of multiple fluid levels and distension of the bowel. The balloon was not visible on the Xray either. An ultrasound examination revealed a bloated intestine up to a diameter of $40 \mathrm{~mm}$ and no peristalsis was observed. The patient underwent an emergency operation with explorative laparotomy. The balloon was found in the small intestine in

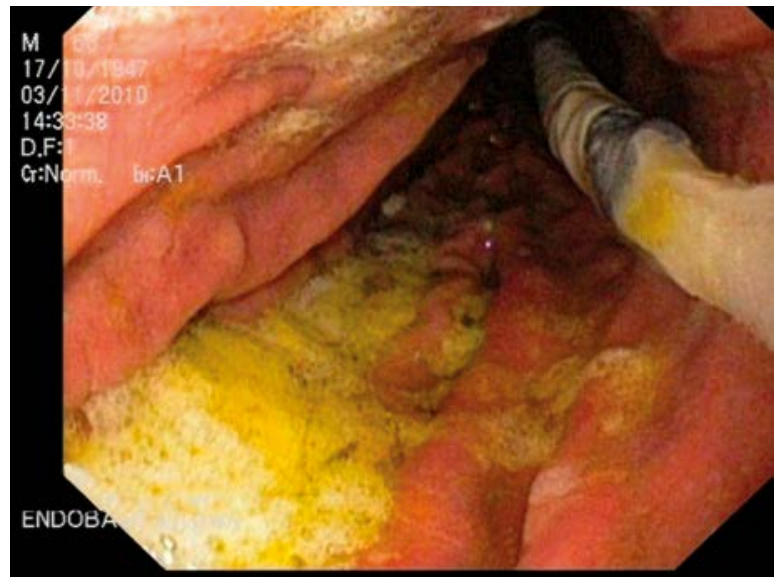

Photo 1. "Heliosphere BAG ${ }^{\circledR}$ " balloon inserted into the stomach

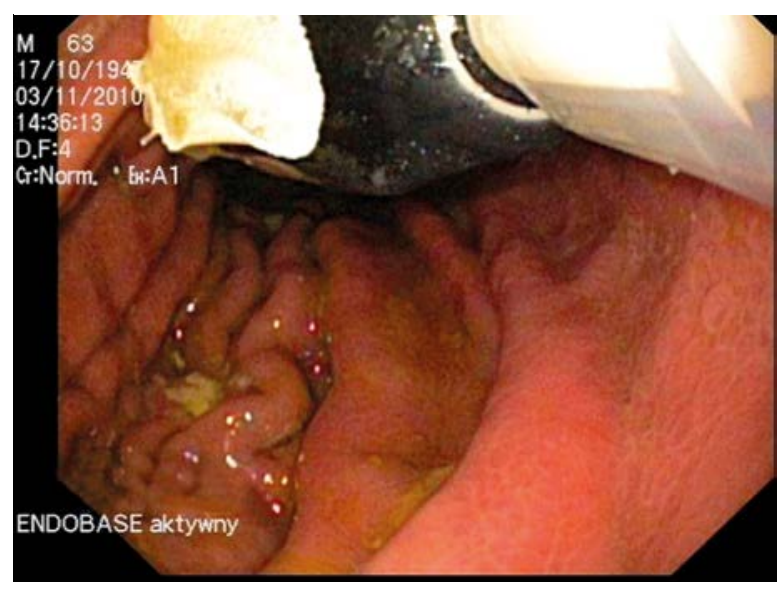

Photo 2. The early stage of "Heliosphere BAG ${ }^{\circledR}$ " balloon filling; the separated balloon sheath can be seen in the foreground

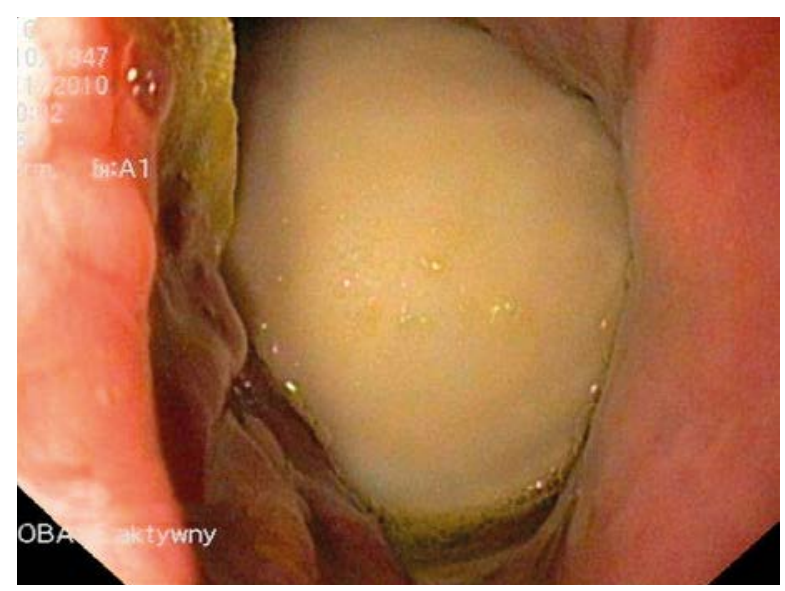

Photo 3. "Heliosphere BAG ${ }^{\circledR}$ " balloon already air-filled 


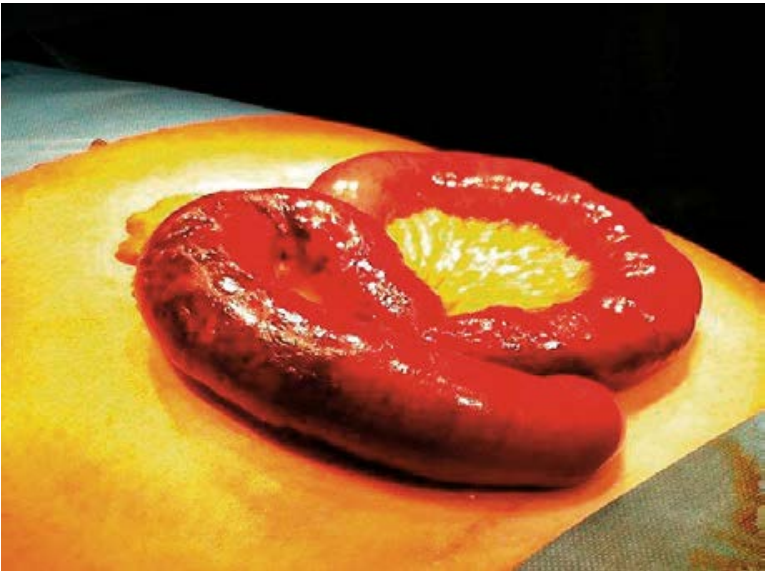

Photo 4. The bowel wall multiple necrosis at the level of the balloon

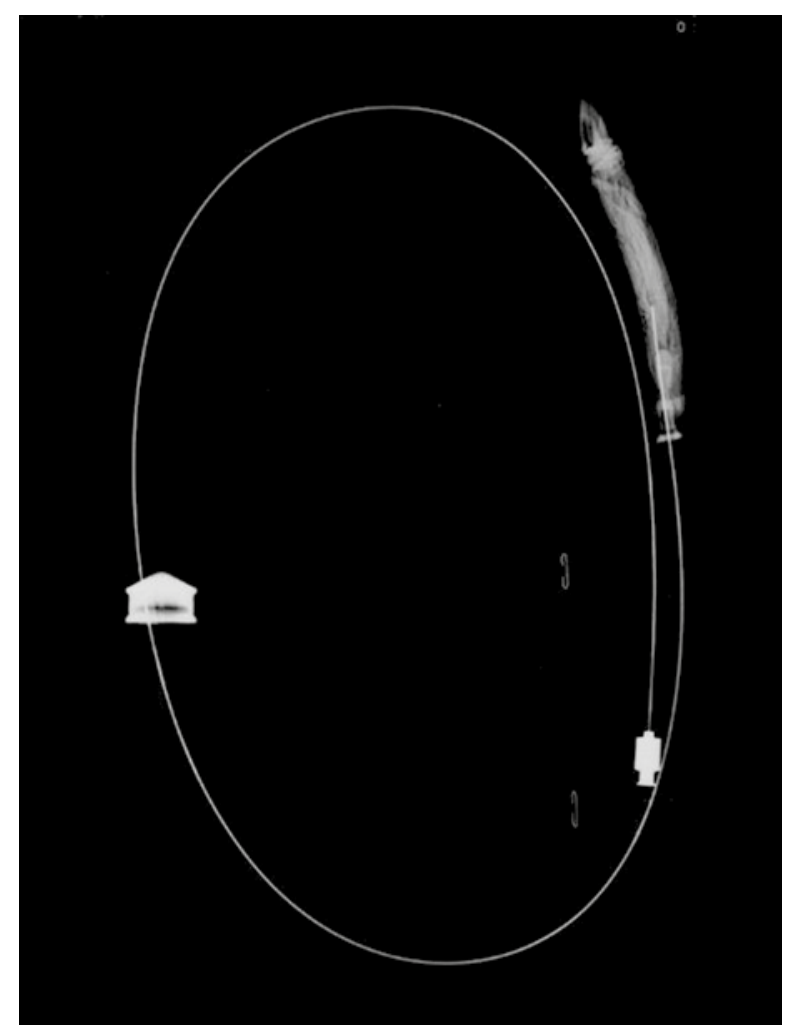

Photo 5. The picture shows a mandrin enabling insertion of a set to a stomach, the balloon sheath, rolled-up balloon and its valve. After the insertion, the balloon left in the stomach on its own remains invisible in $\mathrm{X}$-ray due to losing pressure while migrating into the gastrointestinal tract. Inserting a wire or a net into the balloon wall would make it possible to trace its migration into the gastrointestinal tract the middle section causing complete obstruction of the bowel. This part of the intestine, approximately $20 \mathrm{~cm}$ long, was thickened, oedematous, and changed by multifocal necrosis. This portion of the intestine was removed together with the balloon stuck inside it, still partly filled with air. An end-toend bowel anastomosis was performed. On the $6^{\text {th }}$ day after the operation, the patient was discharged from hospital in good condition. In addition, a histopathological examination revealed a $2 \mathrm{~cm}$ bowel perforation (Photo 4).

\section{Discussion}

Intragastric balloon placement is a very common method of treatment of obesity and is often used by non-surgical teams in endoscopy departments $[14,19]$. The likelihood of spontaneous intragastric balloon damage is a well-known phenomenon [20]. In particular, this concerns patients whose therapy period is extended over 180 days. The diagnosis of a self-deflated fluid-filled balloon is usually not difficult, either for a doctor or for a patient, as this type of balloon contains methylene blue that, having been absorbed by the digestive system, is then excreted with urine. In such cases, an urgent endoscopic procedure allows the deflated balloon to be removed while still located in the stomach. An air-filled balloon, however, can be self-deflated without causing any symptoms, because it is not filled with any substance which could help the diagnosis. A deflated airfilled or fluid-filled balloon can move further down to the distal intestine and can always be a risk for mechanical ileus [21-24]. This is exactly what happened to the described patient, who came to the hospital thinking it was another situation of balloon intolerance. This was also the primary diagnosis made by medical staff after the admission of the patient to the hospital. It was an endoscopic examination that revealed the real cause of his problem and enabled further proper treatment. One of the advised methods in the situation of a self-deflated balloon that has migrated beyond the pylorus is observing the patient and waiting for excretion of the balloon with stool. In the described case, we qualified this patient for emergency surgery due to symptoms of ileus diagnosed by an X-ray and ultrasound examination. The surgical procedure confirmed our diagnosis and the histopathological examination showed how dangerous and life-threat- 
ening the situation was. While analysing this case and the issue of a self-deflated balloon, we must remember that the patient himself prolonged the therapy period by 2 months. In this study, we would like to emphasise the following issues:

- The necessity of removing an air-filled balloon according to the manufacturer's instructions, which would have avoided the described situation.

- Due to the lack of early diagnosis of a self-deflated air-filled balloon, adding a marker (e.g. smell) while inflating the balloon would be advisable and it requires further studies.

- Impossibility of finding the exact balloon location in an abdomen X-ray image (Photo 5).

- The necessity of multidisciplinary specialist team (non-surgeons and surgeons) care along with appropriate diagnostic tools in every case of intragastric balloon insertion.

- When an air-filled balloon is damaged, there are no early, worrying symptoms that can warn a patient. Even a balloon migration deep down the gastrointestinal tract may present few symptoms. Discomfort in the abdominal area, nausea and vomiting were not significant problems for this method of treatment and also for our patient. It was the worsening pain and regurgitation of stomach contents that made the patient contact his doctor. In the described case it was not possible to determine precisely when the balloon got damaged. From the patient's account, we can estimate that it may have happened 3-4 days before the patient came to the hospital.

- The macroscopic and microscopic view of the specimen undoubtedly confirmed that the decision to remove the balloon surgically was the only proper way of treatment and any delay in performing that operation would lead to perforation of the bowel and all consequences of that. It is likely that if the patient had come to the clinic earlier (1-2 days), he would have avoided the partial small bowel resection. In the analysed case, the operation was a necessity. The decision to prolong conservative treatment could be a life risk to the patient and have serious consequences.

\section{Conclusions}

Intragastric balloon treatment is a safe method with great potential. The history of using it so far provides an optimistic outlook giving many patients a chance, in particular those for whom the other methods have been contraindicated. The risk of complications, including the most important complication, which is ileus caused by the balloon, can be considerably diminished if recommendations are strictly fulfilled by a patient, although some of them prolong the therapy by themselves, as described in our article. Non-surgeons who perform the intragastric balloon insertion should be aware that not all self-deflated balloons can pass through the digestive tract and be excreted with stool and in some cases urgent surgical treatment is necessary. Symptoms of ileus can be very helpful during the treatment process although clinical symptoms, especially in super morbidly obese patients, sometimes are not obvious and can be confused with typical consequences of balloon insertion: nausea, vomiting and abdominal pain.

\section{References}

1. Nelson DW, Blair KS, Martin MJ. Analysis of obesity-related outcomes and bariatric failure rates with the duodenal switch vs gastric bypass for morbid obesity. Arch Surg 2012; 147: 847-54.

2. Zhang N, Maffei A, Cerabona T, et al. Reduction in obesity-related comorbidities: is gastric bypass better than sleeve gastrectomy? Surg Endosc 2013; 27: 1273-80.

3. Paluszkiewicz R, Kalinowski P, Wróblewski T, et al. Prospective randomized clinical trial of laparoscopic sleeve gastrectomy versus open Roux-en-Y gastric bypass for the management of patients with morbid obesity. Videosurgery Miniinv 2012; 7 : 225-32.

4. Hady HR, Dadan J, Gołaszewski P, et al. Impact of laparoscopic sleeve gastrectomy on body mass index, ghrelin, insulin and lipid levels in 100 obese patients. Videosurgery Miniinv 2012; 7 : 251-9.

5. Griffith PS, Birch DW, Sharma AM, et al. Managing complications associated with laparoscopic Roux-en-Y gastric bypass for morbid obesity. Can J Surg 2012; 55: 329-36.

6. Hady HR, Dadan J, Sołdatow M, et al. Complications after laparoscopic gastric banding in own material. Videosurgery Miniinv 2012; 7: 166-74.

7. Michalik M, Budziński R, Orłowski M, et al. Splenic infarction as a complication of laparoscopic sleeve gastrectomy. Videosurgery Miniinv 2011; 6: 92-8.

8. Majumder S, Birk J. A review of the current status of endoluminal therapy as a primary approach to obesity management. Surg Endosc 2013; 27: 2305-11.

9. Noria SF, Mikami DJ. Transoral surgery for morbid obesity. World J Gastrointest Endosc 2011; 3: 201-8.

10. Stimac D, Majanović SK. The position of endoscopic procedures in the treatment of obesity. Curr Clin Pharmacol 2013; 8: 238-46.

11. Fogel R, De Fogel J, Bonila Y, et al. Clinical experience of transoral suturing for an endoluminal vertical gastroplasty: 1-year follow-up in 64 patients. Gastrointest Endosc 2008; 68: 51-8. 
12. Schouten R, Rijs CS, Bouvy ND, et al. A multicenter, randomized efficacy study of the EndoBarrier Gastrointestinal Liner for presurgical weight loss prior to bariatric surgery. Ann Surg 2010; 251: 236-43.

13. Pawlik M, Rydzewska G. Therapeutic methods of obesity treatment with intragastric balloon system. Pol Merkur Lekarski 2009; 26: 527-31.

14. Saruc M, Boler D, Karaarslan M, et al. Intragastric balloon treatment of obesity must be combined with bariatric surgery: a pilot study in Turkey. Turk J Gastroenterol 2010; 21: 333-7.

15. Zerrweck C, Maunoury V, Caiazzo R, et al. Preoperative weight loss with intragastric balloon decreases the risk of significant adverse outcomes of laparoscopic gastric bypass in supersuper obese patients. Obes Surg 2012; 22: 777-82.

16. Göttig S, Daskalakis M, Weiner S, et al. Analysis of safety and efficacy of intragastric balloon in extremely obese patients. Obes Surg 2009; 19: 677-83.

17. Escudero Sanchis A, Catalán Serra I, Gonzalvo Sorribes J, et al. Effectiveness, safety, and tolerability of intragastric balloon in association with low-calorie diet for the treatment of obese patients. Rev Esp Enferm Dig 2008; 100: 349-54.

18. Giuricin M, Nagliati C, Palmisano S, et al. Short- and long-term efficacy of intragastric air-filled balloon (Heliosphere ${ }^{\circledR}$ BAG) among obese patients. Obes Surg 2012; 22: 1686-9.

19. Caglar E, Dobrucali A, Bal K. Gastric balloon to treat obesity: filled with air or fluid? Dig Endosc 2013; 25: 502-7.

20. Dumonceau JM. Evidence-based review of the Bioenterics intragastric balloon for weight loss. Obes Surg 2008; 18: 1611-7.

21. Matar ZS, Mohamed AA, Abukhater M, et al. Small bowel obstruction due to air-filled intragastric balloon. Obes Surg 2009; 19: 1727-30.

22. Ozturk A, Akinci OF, Kurt M. Small intestinal obstruction due to self-deflated free intragastric balloon. Surg Obes Relat Dis 2010; 6: 569-71.

23. Zdichavsky M, Beckert S, Kueper M, et al. Mechanical ileus induces surgical intervention due to gastric balloon: a case report and review of the literature. Obes Surg 2010; 20: 1743-6.

24. Moszkowicz D, Lefevre JH. Deflated intragastric ballooninduced small bowel obstruction. Clin Res Hepatol Gastroenterol 2012; 36: 17-9.

Received: 5.03.2013, accepted: 2.06.2013. 